\title{
A COMPLEMENT TO DIANANDA'S INEQUALITY
}

\section{PENG GAO}

Abstract. Let $M_{n, r}=\left(\sum_{i=1}^{n} q_{i} x_{i}^{r}\right)^{\frac{1}{r}}, r \neq 0$ and $M_{n, 0}=\lim _{r \rightarrow 0} M_{n, r}$ be the weighted power means of $n$ non-negative numbers $x_{i}$ with $q_{i}>0$ satisfying $\sum_{i=1}^{n} q_{i}=1$. In particular, $A_{n}=M_{n, 1}$, $G_{n}=M_{n, 0}$ are the arithmetic and geometric means of these numbers, respectively. A result of Diananda shows that

$$
\begin{aligned}
& M_{n, 1 / 2}-q A_{n}-(1-q) G_{n} \geqslant 0, \\
& M_{n, 1 / 2}-(1-q) A_{n}-q G_{n} \leqslant 0,
\end{aligned}
$$

where $q=\min q_{i}$. In this paper, we prove analogue inequalities in the reversed direction.

Mathematics subject classification (2010): 26D15.

Keywords and phrases: Power means.

\section{REFERENCES}

[1] D. I. CARTwright AND M. J. FiELD, A refinement of the arithmetic mean-geometric mean inequality, Proc. Amer. Math. Soc., 71 (1978), 36-38.

[2] P. H. Diananda, On some inequalities of H. Kober, Proc. Cambridge Philos. Soc., 59 (1963), 341346.

[3] P. H. Diananda, “On some inequalities of H. Kober”: Addendum, Proc. Cambridge Philos. Soc., 59 (1963), 837-839.

[4] P. GAO, Ky Fan inequality and bounds for differences of means, Int. J. Math. Math. Sci., 2003 (2003), 995-1002.

[5] P. GAO, On an inequality of Diananda, Int. J. Math. Math. Sci., 2003 (2003), 2061-2068. 